\title{
Nonpharmacological therapies and provision of aids in outpatient dementia networks in Germany: utilization rates and associated factors
}

This article was published in the following Dove Press journal:

Journal of Multidisciplinary Healthcare

21 May 2015

Number of times this article has been viewed

\author{
Markus Wübbeler' \\ Jochen René Thyrian' \\ Bernhard Michalowsky ${ }^{2}$ \\ Johannes Hertel ${ }^{2}$ \\ Franziska Laporte Uribe ${ }^{3}$ \\ Karin Wolf-Ostermann ${ }^{4}$ \\ Susanne Schäfer-Walkmann ${ }^{6}$ \\ Wolfgang Hoffmann ${ }^{2,5}$ \\ 'Interventional Health Care \\ Research Group, German Center \\ for Neurodegenerative Diseases \\ (DZNE) Rostock/Greifswald, ${ }^{2}$ German \\ Center for Neurodegenerative \\ Diseases (DZNE) Rostock/ \\ Greifswald, Greifswald, Germany; \\ ${ }^{3}$ Implementation and Dissemination \\ Research Group, German Center for \\ Neurodegenerative Diseases (DZNE), \\ Witten, Germany; ${ }^{4}$ Department of \\ Human and Health Science, University \\ of Bremen, Bremen, Germany; \\ ${ }^{5}$ Epidemiology of Health Care \\ and Community Health, Institute \\ for Community Medicine, Ernst- \\ Moritz-Arndt-University Greifswald, \\ Greifswald, Germany; ${ }^{\circ}$ nstitute for \\ Applied Social Sciences, Stuttgart, \\ Germany
}

Correspondence: Markus Wübbeler Research Group "Interventional Health Care Research", German Center for Neurodegenerative Diseases (DZNE), Site Rostock/Greifswald, Ellernholzstrasse I-2, Greifswald D-17489, Germany

Tel +493834867506

Fax +49383486 1955।

Email markus.wuebbeler@dzne.de
Background: Nonpharmacological therapies and the provision of aids are described to be supportive in the treatment of persons with dementia (PWDs). These aim to maintain individuals' participation in daily activities as long as possible, to slow the progression of their disease, and to support their independent living at home. However, there is a lack of knowledge about the utilization of therapies and aids among community-dwelling PWDs.

Objective: The aims of the study were a) to describe the utilization of nonpharmacological therapies and aids among community-dwelling PWDs and b) to analyze the factors associated with utilization.

Method: As part of a cross-sectional study of $n=560$ caregivers of PWDs in dementia networks throughout Germany, we assessed sociodemographics, clinical variables, and the utilization of nonpharmacological therapies (physiotherapy [PT], occupational therapy [OT]), and aids (sensory, mobility, and others), using face-to-face interviews and questionnaires.

Results: Approximately every fourth PWD received PT and every seventh PWD received OT. Sensory aids were utilized by $91.1 \%$, personal hygiene aids by $77.2 \%$, mobility aids by $58.6 \%$, and medical aids by $57.7 \%$ of the sample. Regression analysis revealed that the utilization of PT and medical aids was associated with comorbidities (odds ratio [OR] 1.17 and OR 1.27, respectively) and that the utilization of OT and sensory aids was associated with age (OR 1.06 and OR 0.95 , respectively).

Conclusion: The utilization of nonpharmacological therapies and aids among communitydwelling people served by dementia networks is more frequent than that reported for people in other settings. This result indicates that PWDs in integrated care models such as dementia networks receive better health care.

Keywords: aid, integrated care, collaborative care

\section{Introduction}

The increasing number of persons with dementia (PWDs) is one of the most challenging problems for health care systems worldwide. ${ }^{1}$ In Germany, approximately 1.5 million people are affected by dementia, of whom approximately three-quarters are living at home. ${ }^{2}$ Dementia includes pathologies such as Alzheimer's disease, vascular dementia, and frontotemporal dementia. The underlying neurodegenerative process is associated with cognitive dysfunctions in memory, orientation, and conception formation. In most cases, it is also associated with the institutionalization of the PWD. ${ }^{3}$ The global estimation of the prevalence of dementia ranges between $5 \%$ and $7 \%$ among those aged $\geq 60$ years. ${ }^{4}$ Because there is no causal treatment of dementia available and most PWDs want to live at home as long as possible, treatment and care need to focus on 
enabling PWDs to live at home as independently and as long as possible. From the health care system perspective, there are also economic reasons to avoid institutionalization. Current evidence-based guidelines for the treatment of dementia recommend a wide variety of medication and nonpharmacological treatment options. ${ }^{5-7}$ Important nonpharmacological treatment options are physiotherapy (PT) and occupational therapy (OT). There is an overlap in the goals of PT and OT, as both aim to maintain individuals' functioning in everyday living. However, PT focuses on physical abilities, such as mobility and balance, whereas the focus of OT is more on the improvement and support of the patient's activities of daily living. Both therapies increase or maintain the PWDs' stability and thus reduce the need for care, potentially resulting in less burden on the caregivers. ${ }^{8-11}$ Other nonpharmacological treatment options to support PWDs and their caregivers include the provision of medical aids. According to Pynoos and Ohta, ${ }^{12}$ the provision of aids is associated with an easier and safer caring situation for PWDs. Although nonpharmacological therapies, such as PT and OT, and aids, seem to be beneficial, there is limited knowledge about the utilization of these resources among community-dwelling PWDs. The utilization rates vary between $7 \%{ }^{13}$ among PWDs and $25 \%{ }^{14}$ among people aged approximately 80 years in the German general population. However, more detailed information about different therapies is missing. Studies that examine different aids are also lacking. One study reported that $59 \%$ of PWDs used aids, such as walkers, incontinence products, hearing aids, and surgical stockings, but did not differentiate between these aids. ${ }^{15}$ Secondary data indicate a rate of $34 \%$ utilization among females and $28 \%$ utilization among males in the general population, again without examining the distribution of aids. ${ }^{14}$ Detailed knowledge about the different therapies and aids that are used by community-dwelling PWDs and factors associated with utilization could help to identify potential gaps in the treatment and risk factors for undersupply.

Dementia networks (DNs) in Germany fit the World Health Organization's (WHO) 2008 definition of integrated care:

The management and delivery of health services so that clients receive a continuum of preventive and curative services, according to their needs over time and across different levels of the health system. ${ }^{16}$

The WHO characterizes the focus of integrated care models as ranging from a focus on care providers to a focus on users. Models for providers focus on management, service integration, and evaluation. User-oriented models strive for seamless, smooth, and easy navigation for patients. For example, DNs in Germany are organized as follows:

The DN provides an interdisciplinary, cooperative model between various medical care disciplines. The network includes specialized physicians in private practice, hospitals, and medical and social institutions. There are two main goals - an early and differential formal diagnosis, and a personcentered and comprehensive therapy according to the progression of the syndrome. To achieve these goals, the DN has to establish a specific dementia care pathway in its network.

The present analysis aimed to a) describe the utilization of PT/OT and aids, and b) analyze the association between sociodemographic and clinical variables and the utilization of nonpharmacological therapies, including care aids, among community-dwelling PWDs.

\section{Materials and methods \\ Sample}

The present analysis is based on cross-sectional data from the Dementia Networks in Germany (DemNet-D) study (unpublished data, March 2015). The DemNet-D was conducted to analyze $n=13$ different DNs and their clients, using both qualitative and quantitative methods. The ethics committee at the medical faculty of Greifswald University approved the study (approval number BB 107/12).

In recent years, DNs have been established in Germany to address the fragmentation of dementia-specific services in the health care system and to improve integrated care for PWDs. The DNs can be defined as an approach that links different dementia support services and stakeholders to bridge the treatment gap in ongoing medical and social care. These DN applied for funding to participate and were chosen by the funding agency - the Federal Ministry of Health (BMG). Inclusion criteria were: a) having been previously evaluated; and $b$ ) being considered a sustainable DN.

The inclusion criteria for PWDs and their caregivers in this analysis were as follows: a) the PWD had to be a client in one of the 13 participating DNs; b) both the PWD and his or her caregiver provided written informed consent for participation in the study; c) the PWD had to live in the community, ie, not live in a residential care facility or not be permanently hospitalized; and d) caregivers had to be able to provide detailed information on the PWD. Recruitment was conducted by employees of the participating DNs.

\section{Data assessment}

Trained interviewers conducted the comprehensive data assessment via face-to-face interviews, and pencil and 
paper questionnaires. Between February and September 2013, n=560 PWDs and their respective caregivers were interviewed. The assessment solicited data about sociodemographic variables, clinical variables, and variables characterizing the utilization of therapies and aids. The total number of interviews conducted by each DN ranged from 17 up to 61 ( $\mathrm{n}=61$ for one $\mathrm{DN}, \mathrm{n}=56$ for three DNs, $\mathrm{n}=54$ for two DNs, $\mathrm{n}=44$ for one $\mathrm{DN}, \mathrm{n}=41$ for two DNs, $\mathrm{n}=38$ for one $\mathrm{DN}, \mathrm{n}=22$ for one DN, $n=20$ for one $\mathrm{DN}$, and $\mathrm{n}=17$ for one $\mathrm{DN}$ ). The sociodemographic variables that were used for the present analysis were as follows: sex, age, living situation (alone/ not alone), region (rural/urban), and socioeconomic status. Socioeconomic status was operationalized according to the Scheuch-Winkler-Index, ${ }^{17}$ which considers the education, income, and former occupational status of the PWD. This index yields a categorization into three socioeconomic classes (high, middle, and low).

The clinical variables that were used for this analysis included functional impairment and functional disabilities related to cognition, comorbidity, and dementia diagnoses. Functional impairment was assessed using Lawton and Brody's Instrumental Activities of Daily Living (IADL) score.$^{18}$ This instrument quantifies impairment using a range between 8 points (no impairment) and 0 points (highest level of impairment in activities of daily living). Dementia-related functional disabilities were assessed using the Functional Assessment Staging (FAST) scale, ${ }^{19}$ an instrument that yields seven stages from 1 (no disability) to 7 (very severe disability). The FAST instrument is an observational instrument and, therefore, is applicable to all stages of the dementia syndrome. Comorbidities were assessed using a list of the most common geriatric diseases, to minimize recall bias. For each condition, the interviewers asked whether a formal diagnosis had been provided by a physician. Additional nonlisted diseases could be added in open-text fields. For data analysis, the diagnoses were coded based on the International Classification of Diseases and Related Health Problems (ICD-10). ${ }^{20}$ Furthermore, we asked the patients' caregivers whether the PWD had received a formal diagnosis of dementia, and if so, the type of dementia was specified.

To collect data about the utilization of therapies, we asked the caregiver to state whether the PWD had received OT and PT in the last 6 months and how often the PWD had received the different therapy modalities. To assess the utilization of aids in the care arrangement, we presented a list of the most common medical aids and asked whether these aids were currently used. We collected information on sensory aids (hearing aid, glasses), personal hygiene aids (nursing bed, nursing covers, nursing insets, toilet chair, toilet seat, bathtub seat, bath lifter, handles, decubitus mattress), mobility aids (wheelchair, stair lifter, walking stick, crutch, walker), and medical aids (sphygmomanometer, blood glucose meter, peak flow meter).

To reduce the heterogeneity and account for the different goals of the DNs, we categorized the networks into "physicianassociated" networks and "other" networks. In five of the participating networks, the head of the network was a neurologist/ psychiatrist, which could play an important role in our analysis because it can be assumed that the prescription of therapies and aids in such networks differs from that in the other DNs.

\section{Statistical analysis}

We used descriptive statistics to describe the sample. We presented data for the whole sample as well as separately for each category of network, applying statistical tests (one-sample $t$-test, chi-square test, Mann-Whitney $U$ test, and Fisher's exact test) for the differences between physician-associated networks and the other networks.

To evaluate the association between the utilization of aids and therapies and the sociodemographic and clinical variables, we fitted multiple logistic regression models with utilization as a dichotomous (yes vs no) outcome variable. We adjusted for age, sex, comorbidities, IADL, ${ }^{18}$ area of residence (rural vs urban), and category of network (physician-associated vs other), to reduce confounding. We included the network as a random effect in our model. $P$-values were calculated according to two-tailed significance level $(P$-value $\leq 0.05)$. The statistical analysis was performed using the software package STATA 11 (StataCorp LP, Texas, USA).

\section{Results \\ Sample characteristics}

The sample is described in detail in Table 1.

According to the Scheuch-Winkler-Index, the socioeconomic level of the study population was predominantly the low social class $(60.6 \%$ in class 1$)$. The clients were more likely to live in an urban environment (82\%) than a rural environment. Common comorbidities were cardiovascular disease $(n=420[81 \%])$, with a total of 755 ICD-10 cardiovascular diagnoses, and orthopedic diseases ( $n=301$ [58\%]), with a total of 441 ICD-10 diagnoses in the sample. The mean age and proportion of males/females differed significantly between the physician-associated networks and other networks. The users of the other networks were, on average, 2.4 years older $(P \leq 0.001)$. In these other networks, $58 \%$ of the users were females $(P \leq 0.001)$. Significant differences between 
Table I Sociodemographic and clinical characteristics of the total study sample $(n=560)$ and differences between physician-associated networks $(n=203)$ and other networks $(n=357)$

\begin{tabular}{|c|c|c|c|c|c|c|c|}
\hline Variable & Measure & Statistic & $\begin{array}{l}\text { Missing } \\
\text { values* }\end{array}$ & $\begin{array}{l}\text { Total } \\
n=560\end{array}$ & $\begin{array}{l}\text { Physician-associated } \\
\text { networks } \\
n=203\end{array}$ & $\begin{array}{l}\text { Other } \\
\text { networks } \\
n=357\end{array}$ & $P$-value \\
\hline Age & Years & Mean (SD) & 5 & $79.7(8.4)$ & $77.9(8.0)$ & $80.3(8.8)$ & $P \leq 0.00 I^{a}$ \\
\hline Sex & Female & Frequency & 3 & $325(58.3 \%)$ & 100 (49.2\%) & $225(63.5 \%)$ & $P \leq 0.00 I^{d}$ \\
\hline \multirow[t]{4}{*}{ Social index } & Scheuch-Winkler (index) & Frequency & $|5|$ & & & & \\
\hline & Low & & & $248(60.6 \%)$ & $88(59.1 \%)$ & $160(61.5 \%)$ & $P=0.164^{b}$ \\
\hline & Middle & & & $|2|(29.6 \%)$ & $4 \mathrm{I}(27.5 \%)$ & $80(30.7 \%)$ & \\
\hline & High & & & $40(9.8 \%)$ & $20(13.4 \%)$ & $20(7.7 \%)$ & \\
\hline Formal diagnosis & Yes & Frequency & 18 & $503(92.8 \%)$ & 177 (92.2\%) & $326(93.1 \%)$ & $P=0.729^{d}$ \\
\hline Type of dementia & & Frequency & 84 & & & & \\
\hline Alzheimer's dementia & & & & $211(44.3 \%)$ & 81 (50.6\%) & $130(4 \mid .1 \%)$ & $P=0.374^{b}$ \\
\hline Vascular dementia & & & & $92(19.3 \%)$ & $24(\mid 5.0 \%)$ & $68(21.5 \%)$ & \\
\hline Unspecific & & & & $155(32.6 \%)$ & $50(31.3 \%)$ & $105(33.2 \%)$ & \\
\hline Others & & & & $18(3.8 \%)$ & $5(3.1 \%)$ & 13 (4.1\%) & \\
\hline Region & Rural & Frequency & 7 & $100(18.1 \%)$ & $4 \mathrm{I}(20.4 \%)$ & $59(16.8 \%)$ & $P=0.302^{d}$ \\
\hline Living & Alone & Frequency & 2 & $119(21.3 \%)$ & $34(16.9 \%)$ & $85(23.9 \%)$ & $P=0.067^{d}$ \\
\hline Cognitive impairment & FAST stage $(I-7)$ & Median & 20 & 6.0 & 6.0 & 7.0 & $P \leq 0.005^{c}$ \\
\hline Functional status & IADL score (0-8) & Mean (SD) & 49 & $1.9(1.8)$ & $2.8(2.0)$ & $1.5(1.6)$ & $P \leq 0.005^{\mathrm{a}}$ \\
\hline Comorbidity & Number of morbidities & Mean (SD) & 39 & $3.9(2.1)$ & $3.6(1.9)$ & $4(2.2)$ & $P=0.012^{\mathrm{a}}$ \\
\hline Age (caregiver) & Years & Mean (SD) & 5 & $63.9(12.9)$ & $66.0(13.4)$ & $62.6(12.5)$ & $P \leq 0.005^{\mathrm{a}}$ \\
\hline Sex (caregiver) & Female & Frequency & 5 & $416(74.9 \%)$ & 147 (72.8\%) & $269(76.2 \%)$ & $P=0.415^{d}$ \\
\hline Caregiver relationship & Yes & Frequency & 2 & & & & \\
\hline Spouse/partner & & & & $280(50.2 \%)$ & 129 (63.9\%) & $15 \mathrm{I}(42.3 \%)$ & $P \leq 0.00 I^{b}$ \\
\hline Daughter/son & & & & $206(36.9 \%)$ & $67(33.2 \%)$ & $139(39.0 \%)$ & \\
\hline Daughter/son-in-law & & & & $21(3.8 \%)$ & I $(0.5 \%)$ & $20(5.6 \%)$ & \\
\hline Others & & & & $51(9.1 \%)$ & $5(2.5 \%)$ & $46(12.9 \%)$ & \\
\hline
\end{tabular}

Notes: *Cases with missing values were excluded from the calculation of frequencies and means. ${ }^{\mathrm{O} O n e-s a m p l e ~} t$-test; ${ }^{\mathrm{b}}$ chi-square test; 'Mann-Whitney $U$ test; ${ }^{\mathrm{d}} \mathrm{Fisher}$ 's exact test. Abbreviations: FAST, Functional Assessment Staging; IADL, Instrumental Activities of Daily Living; SD, standard deviation.

physician-associated networks and the other networks were also found for cognitive impairment, comorbidities, functional abilities, and relationship of the caregivers. Significantly fewer PWDs in physician-associated networks were less cognitively impaired according to the FAST scale $(P<0.005)$. The level of functional abilities was lower in the group of PWDs in the other networks $(P<0.005)$. PWDs in the other networks also stated a greater number of comorbidities $(P=0.012)$. The majority of family caregivers in physician-associated networks were spouses $(P \leq 0.001)$ (Table 1$)$.

\section{Utilization of therapies and aids}

PWDs used PT more often than OT (24.4\% vs $15.8 \%)$. PT was the most frequently used therapy in both network groups (26.0\% and $21.3 \%$ ). Users of the other networks stated a difference between PT and OT utilization (26.0\% PT vs $14.0 \%$ OT, respectively), whereas PWDs in physician-associated networks reported OT utilization rates that were closer to the rates of PT utilization (21.3\% PT vs 19.2\% OT, respectively). However, significant differences were not found for the utilization of therapy or for the number of sessions (Table 2).
Overall, PWDs often received sensory aids (91.1\%), personal hygiene aids (77.2\%), mobility aids (58.6\%), and medical aids (57.5\%). The proportions of mobility aids were significantly higher for PWDs in other networks $(65.2 \%$ vs 46.7\%) ( $P \leq 0.001)$. Of PWDs in other networks, $84.9 \%$ had received personal hygiene aids, compared with $65.0 \%$ of clients of medical-associated networks $(P \leq 0.001)$. In contrast to the findings concerning nursing and mobility aids, PWDs in physician-associated networks had received significantly more medical $(+7.9 \%)(P=0.017)$ and sensory aids $(+6.3 \%)$ $(P=0.019)$ (Table 2).

\section{Association between utilization and sociodemographic and clinical variables}

In the multivariable regression model for therapies, we found that comorbidities and age were associated with therapy utilization. The odds of utilizing OT increased with higher age (odds ratio $[\mathrm{OR}] 1.07, P \leq 0.001$ ), and the odds of utilizing PT increased with more comorbidities (OR 1.17, $P=0.023$ ). All other variables in the regression model were not statistically significant (Table 3). 
Table 2 Utilization of nonpharmacological therapies and provision of aids for the total study sample $(\mathrm{n}=560)$ and differences between physician-associated networks $(n=203)$ and other networks $(n=357)$

\begin{tabular}{|c|c|c|c|c|c|c|c|}
\hline Variable & Measure & Statistic & $\begin{array}{l}\text { Missing } \\
\text { values* }\end{array}$ & $\begin{array}{l}\text { Total } \\
n=560\end{array}$ & $\begin{array}{l}\text { Physician-associated } \\
\text { networks } \\
\mathrm{n}=203\end{array}$ & $\begin{array}{l}\text { Other } \\
\text { networks } \\
n=357\end{array}$ & $P$-value \\
\hline \multirow[t]{2}{*}{ Physiotherapy } & Treatment (yes) & Frequency & 55 & $123(24.4 \%)$ & $37(21.3 \%)$ & $86(26.0 \%)$ & $P=0.276^{b}$ \\
\hline & Number visits per PWD & Mean (SD) & 11 & $21.4(16.2)$ & $16.5(14.6)$ & $23.1(16.5)$ & $P=0.065^{a}$ \\
\hline Occupational & Treatment (yes) & Frequency & 66 & $78(15.8 \%)$ & $33(19.2 \%)$ & 45 (I4.0\%) & $P=0.154^{b}$ \\
\hline therapy & Number visits per PWD & Mean (SD) & 5 & $20.9(\mid 2.9)$ & $19.5(12.4)$ & $21.9(13.3)$ & $P=0.435^{\mathrm{a}}$ \\
\hline \multirow{2}{*}{ Mobility aid } & Yes & Frequency & & $328(58.6 \%)$ & 95 (46.7\%) & $233(65.2 \%)$ & $P \leq 0.00 I^{b}$ \\
\hline & Number of aids per PWD & Mean (SD) & & $\mathrm{I} .0(\mathrm{I} . \mathrm{I})$ & $0.8(1.0)$ & $1.2(1.1)$ & $P \leq 0.00 I^{a}$ \\
\hline Personal & Yes & Frequency & & 435 (77.7\%) & $132(65.0 \%)$ & $303(84.9 \%)$ & $P \leq 0.00 \mathrm{I}^{\mathrm{b}}$ \\
\hline hygiene aid & Number of aids per PWD & Mean (SD) & & $2.4(2.0)$ & $1.7(1.8)$ & $2.8(2.1)$ & $P \leq 0.00 I^{a}$ \\
\hline \multirow[t]{2}{*}{ Medical aid } & Yes & Frequency & & $323(57.7 \%)$ & $127(62.6 \%)$ & $196(54.9 \%)$ & $P=0.017^{b}$ \\
\hline & Number of aids per PWD & Mean (SD) & & $0.7(0.7)$ & $0.8(0.7)$ & $0.7(0.7)$ & $P=0.993^{\mathrm{a}}$ \\
\hline \multirow[t]{2}{*}{ Sensory aid } & Yes & Frequency & & $510(91.1 \%)$ & 193 (95.1\%) & 317 (88.8\%) & $P=0.019^{b}$ \\
\hline & Number of aids per PWD & Mean (SD) & & I.I (0.5) & I.2(0.5) & I.I (0.6) & $P=0.780^{a}$ \\
\hline
\end{tabular}

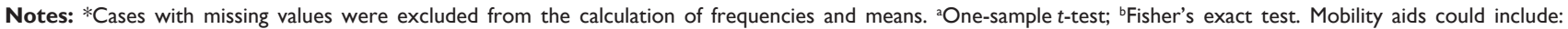
wheelchair, stair lifter, walking stick, crutch, or walker. Personal hygiene aid could include: nursing bed, nursing covers, nursing insets, toilet chair, toilet seat, bathtub seat, bath lifter, handles, or decubitus mattress. Medical aid could include: sphygmomanometer, blood glucose meter, or breath intake meter. Sensory aid could include: hearing aid or glasses.

Abbreviations: PWD, person with dementia; SD, standard deviation.

In the logistic regression models for use of aids, sex was a significant covariate in two of the four regression models (Table 4). In the models for both nursing care (OR 2.75, $P \leq 0.001)$ and mobility aids (OR 1.77, $P=0.019$ ), female users showed higher odds of utilization compared with male users of networks. Nursing care aids were also associated with functional limitations (OR $0.61, P \leq 0.001$ ), increased number of comorbidities (OR 1.38, $P \leq 0.001$ ), and higher age (OR 0.94, $P \leq 0.001$ ). Similar associated factors were found in the model for mobility aids. Within this model, age (OR 0.92, $P \leq 0.001$ ), number of comorbidities (OR 1.45, $P \leq 0.001$ ), and functional limitations (OR $0.70, P \leq 0.001$ ) were significantly associated factors. For the medical and sensory aids, we found different associations between these factors. Whereas medical aids were solely associated with the number of comorbidities (OR 1.27, $P \leq 0.001$ ), we found that sensory aids were significantly associated with age (OR 0.95 , $P=0.007)$ and the physician-association networks (OR 2.11, $P=0.038$ ) (Table 4).

\section{Discussion}

The aim of this analysis was to determine the utilization rates of nonpharmacological therapies and aids among PWDs and to analyze the factors associated with the utilization of these therapies and aids. To our knowledge, this is the first study to differentiate between the utilization of different therapy modalities and types of aids among community-dwelling PWDs. This makes direct comparisons with other studies difficult, but trends can be discussed.

Our results indicate higher utilization rates of nonpharmacological therapies in German DNs than those found in other studies. About every fourth PWD received PT and

Table 3 Multivariable associations between physiotherapy and occupational therapy, network association, sociodemographic, and clinical variables

\begin{tabular}{|c|c|c|c|c|c|c|c|c|}
\hline \multirow[t]{3}{*}{ Variables } & \multicolumn{8}{|c|}{ Therapy - logistic regression } \\
\hline & \multicolumn{4}{|c|}{ Physiotherapy } & \multicolumn{4}{|c|}{ Occupational therapy } \\
\hline & OR & $95 \% \mathrm{Cl}$ & & $P$-value & OR & $95 \% \mathrm{Cl}$ & & $P$-value \\
\hline Sex (female) & 0.973 & 0.692 & 1.368 & 0.877 & 0.773 & 0.328 & 1.825 & 0.558 \\
\hline Age & 1.032 & 0.988 & 1.077 & 0.146 & 1.056 & 1.027 & 1.085 & $\leq 0.001$ \\
\hline Number comorbidities & 1.167 & 1.021 & 1.334 & 0.023 & 1.068 & 0.926 & 1.232 & 0.361 \\
\hline Functional status (IADL) & 0.906 & 0.798 & 1.029 & 0.130 & 0.973 & 0.860 & 1.100 & 0.664 \\
\hline Network (medical) & 0.792 & 0.423 & 1.485 & 0.469 & 1.340 & 0.744 & 2.414 & 0.328 \\
\hline Region (rural) & 0.885 & 0.487 & 1.608 & 0.690 & 0.579 & 0.280 & 1.198 & 0.141 \\
\hline
\end{tabular}

Abbreviations: $\mathrm{Cl}$, confidence interval; IADL, Instrumental Activities of Daily Living; OR, odds ratio. 


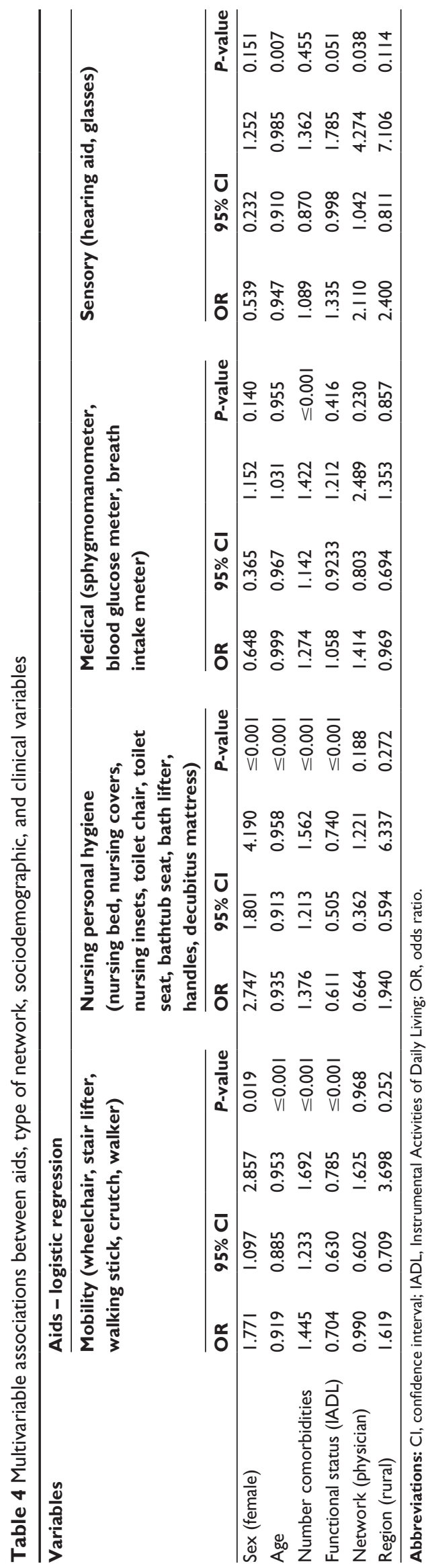

every seventh PWD received OT in the current study. The data of 1.8 million people (provided by a health insurance company) have shown a nonpharmacological therapy utilization rate of $25 \% .{ }^{14}$ The group of PWDs showed lower rates of nonpharmacological therapies. Duru et al ${ }^{13}$ evaluated a coordinated care intervention for PWDs and included 408 patients in their analysis. The authors outlined the utilization rates of nonpharmacological therapies, considering PT, OT, and speech therapy as a common category, and stated that $6.5 \%$ of the sample used nonpharmacological therapies. Köhler et $\mathrm{al}^{21}$ analyzed the utilization of therapies in a sample of 235 PWDs who were integrated in a DN. In their analysis, only $3.1 \%$ of the participants received OT. This difference ( $3.1 \%$ vs $15.8 \%$ in the current study) might be related to a lack of therapists within the rural area or the focus of the evaluated DN.

In our data, the utilization of PT was associated with an increased number of comorbidities (OR 1.17), and the utilization of OT was associated with age (OR 1.06). The association between PT and comorbidities was expected because $28 \%(n=157)$ of participants in our study reported a diagnosis of orthopedic diseases of the spine, for which PT is a common intervention. However, the association between OT and age is inconsistent with the findings of Rothgang et al. ${ }^{22}$ Based on the data of 8.3 million people (provided by a German health insurance company), the authors found lower prescription rates of OT in older PWDs compared with younger PWDs. Additionally, they found that people without dementia used OT and PT more frequently. The authors attributed the increased utilization of OT and PT among nondemented people to clinical conditions rather than dementia status. In our sample, the significantly higher OT utilization in older PWDs might be related to the cognitive decline of the clients. However, without data to quantify the degree of cognitive impairment of the participants, we cannot provide an explicit answer for this assumption. Although OT in the German health system is frequently used to maintain the functional abilities of patients, the functioning score in the current sample was not a significant predictor $(P=0.664)$ in the regression model.

Aids are common in the health care arrangement of PWDs, but comparisons with other studies are difficult. Previously published studies do not provide a differentiation between the types of aids. In a sample of 176 PWDs, Leicht et $\mathrm{al}^{15}$ summarized aids in a category containing walkers, incontinence products, hearing aids, surgical stockings, and dental crowns. The utilization rates demonstrated by Leicht et al were $59.1 \%$ for the whole group of aids and 
dental prostheses. There was a high rate of utilization of aids in the current sample. The rates ranged from $59 \%$, for mobility aids, to $91 \%$, for sensory aids. We also found significant associations with sex in two of the aid regression models. Female participants showed higher odds of aids use in the group of mobility and nursing care. This result seems to be comparable with the findings of Kemper et al, ${ }^{14}$ who found that $34 \%$ of females and $28 \%$ of males were supplied with aids. Overall, the utilization numbers underline the important role of aids in the home environment. Our results illustrate the relevance of clinical and sociodemographic variables that are associated with the provision of aids. We found a negative association between age and utilization. It could be expected that older patients use aids more frequently than do younger patients, but our results show the opposite association. This result implies that higher age is a risk factor for decreasing utilization even though both health status and cognitive impairment are negatively associated.

\section{Limitations}

There were two major limitations of this study. First, there was no information about the specific indication of the therapy or aid used. Therefore, we could not evaluate whether the rate of utilization shows an adequate supply or an overor undersupply. We were aware of this limitation and, thus, were careful in the interpretation of the results. Second, the generalizability of the results was limited to participants of DNs. DNs have been established to address the needs of PWDs; thus, it might be assumed that utilization is higher or more adequate among such participants than among PWDs in the general population or in primary care. However, to our knowledge, there are no population-based studies with PWDs that examine utilization. Rather, studies examine either a more specific setting (such as participants in intervention trials or memory clinics) or use secondary data, which encounters other methodological limitations. Nevertheless, we think our results add to the current knowledge about utilization and the factors associated with it, and provide hints concerning where the adequacy of treatment and care should be more deeply evaluated.

\section{Conclusion}

PWDs in DNs use nonpharmacological therapies and aids, especially PT and OT, more often than do PWDs in other settings. The utilization of aids is positively associated with the number of comorbidities and the degree of functional impairment. The results underline the importance of settings such as DNs to improve utilization in the home environment.
DNs might be better able to address the needs of therapies and aids. However, it remains unclear whether the rate of utilization is adequate at the population level. Therefore, further studies should consider the results of standardized medical examinations.

\section{Acknowledgments}

This study was funded by the Federal Ministry of Health (BMG) of Germany funding scheme "Zukunftswerkstatt Demenz" (grant numbers IIA5-2512FSB031 and IIA5-2512FSB032).

We gratefully thank the participating users of DNs for their time and effort in providing the data. Furthermore, we appreciate the cooperation and exchange with the members of each DN.

\section{Disclosure}

The authors report no conflicts of interest in this work.

\section{References}

1. World Health Organization. Dementia: A Public Health Priority. Geneva: World Health Organization; 2012.

2. Bickel H. Das Wichtigste 1: Die Epidemiologie der Demenz [The Epidemiology of Dementia]. Berlin: Deutsche Alzheimer Gesellschaft e.V. 2012. German.

3. Schulze J, van den Bussche H, Kaduszkiewicz H, Koller D, Hoffmann F. Institutionalization in incident dementia cases in comparison to age- and sex-matched controls: a 5-year follow-up from Germany. Soc Psychiatry Psychiatr Epidemiol. 2015;50(1):143-151.

4. Prince M, Bryce R, Albanese E, Wimo A, Ribeiro W, Ferri CP. The global prevalence of dementia: a systematic review and metaanalysis Alzheimers Dement. 2013;9(1):63-75. e2.

5. S-3 Leitlinie "Demenzen" (Langversion). [S-3 "Dementia" Guideline]. Deutsche Gesellschaft für Psychiatrie, Psychotherapie und Nervenheilkunde (DGPPN); Deutsche Gesellschaft für Neurologie (DGN); 2009. Available from: www.alzheimer-bayern.de/pdf_antraege/ S3LeitlinieDemenz.pdf. Accessed January 8, 2015. German

6. Deutsche Gesellschaft für Allgemeinmedizin und Familienmedizin. Demenz DEGAM - Leitlinie Nr. 12 [Dementia - Guideline No. 12]. Düsseldorf: Deutsche Gesellschaft für Allgemeinmedizin und Familienmedizin (DEGAM); 2008. German.

7. National Collaborating Centre for Mental Health (UK). Dementia: A NICE-SCIE Guideline on Supporting People with Dementia and their Carers in Health and Social Care. Leicester: The British Psychological Society; 2007.

8. Graff MJ, Vernooij-Dassen MJ, Thijssen M, Dekker J, Hoefnagels WH, Rikkert MG. Community based occupational therapy for patients with dementia and their care givers: randomised controlled trial. BMJ. 2006; 333(7580):1196.

9. Graff MJ, Vernooij-Dassen MJ, Thijssen M, Dekker J, Hoefnagels WH, Olderikkert MG. Effects of community occupational therapy on quality of life, mood, and health status in dementia patients and their caregivers: a randomized controlled trial. J Gerontol A Biol Sci Med Sci. 2007;62(9):1002-1009.

10. Lau DT, Scandrett KG, Jarzebowski M, Holman K, Emanuel L. Health-related safety: a framework to address barriers to aging in place. Gerontologist. 2007;47(6):830-837.

11. Rolland Y, Pillard F, Klapouszczak A, et al. Exercise program for nursing home residents with Alzheimer's disease: a 1-year randomized, controlled trial. J Am Geriatr Soc. 2007;55(2):158-165. 
12. Pynoos J, Ohta RJ. In-home interventions for persons with Alzheimer's disease and their caregivers. Phys Occup Ther Geriatr. 1991;9(3-4): 83-92.

13. Duru OK, Ettner SL, Vassar SD, Chodosh J, Vickrey BG. Cost evaluation of a coordinated care management intervention for dementia. Am J Manag Care. 2009;15(8):521-528.

14. Kemper C, Sauer K, Glaeske G. GEK-Heil-und Hilfsmittel-Report 2009 [GEK - Therapy and Aids Report 2009]. Bremen: GEK - Gmünder Ersatzkasse; 2009. German.

15. Leicht H, Heinrich S, Heider D, et al; AgeCoDe study group. Net costs of dementia by disease stage. Acta Psychiatr Scand. 2011;124(5): 384-395.

16. Integrated Health Services - What And Why? Technical Brief No.1, 2008. World Health Organization; 2008. Available from: www.who. int/healthsystems/service_delivery_techbrief1.pdf. Accessed January $8,2015$.

17. Winkler J, Stolzenberg H. Der sozialschichtindex im bundesgesundheitssurvey [Social class index in the Federal Health Survey]. Gesundheitswesen. 1999;61(Suppl 2):S178-S183. German.
18. Lawton MP, Brody EM. Assessment of older people: self-maintaining and instrumental activities of daily living. Gerontologist. 1969;9(3): 179-186.

19. Reisberg B, Jamil IA, Khan S, et al. Staging dementia. In: AbouSaleh MT, Katona C, Kumar A. Principles and Practice of Geriatric Psychiatry. Chichester: John Wiley \& Sons, Ltd; 2011:162-169.

20. ICD-10-GM Version 2013. Internationale statistische Klassifikation der Krankheiten und verwandter Gesundheitsprobleme 10. [International Classification of Diseases and Related Health Problems 10 (ICD-10)]. Revision. German Modification. Version 2013. German Institute of Medical Documentation and Information (DIMDI); 2013. Available from: https:// www.dimdi.de/static/de/klassi/icd-10-gm/kodesuche/onlinefassungen/ htmlgm2013/index.htm. Accessed January 8, 2015. German.

21. Köhler L, Meinke-Franze C, Hein J, et al. Does an interdisciplinary network improve dementia care? Results from the IDemUck-study. Curr Alzheimer Res. 2014;11(6):538-548.

22. Rothgang H, Iwansky S, Müller R, Sauer S, Unger R. Barmer GEK Pflegereport 2010 [GEK Nursing Report 2010]. Schwäbisch Gmünd: Barmer GEK; 2010. German.
Journal of Multidisciplinary Healthcare

\section{Publish your work in this journal}

The Journal of Multidisciplinary Healthcare is an international, peerreviewed open-access journal that aims to represent and publish research in healthcare areas delivered by practitioners of different disciplines. This includes studies and reviews conducted by multidisciplinary teams as well as research which evaluates the results or conduct of such teams or

\section{Dovepress}

healthcare processes in general. The journal covers a wide range of areas and welcomes submissions from practitioners at all levels, from all over the world. The manuscript management system is completely online and includes a very quick and fair peer-review system. Visit http://www.dovepress.com/testimonials.php to read real quotes from published authors. 